\title{
PLANT COLLECTING FOR THE ECOLOGICAL GARDEN AND THE SCOTTISH HEATH GARDEN AT THE ROYAL BOTANIC GARDEN EDINBURGH
}

\author{
Gordon Schofield ${ }^{1}$ Andrew McGinn ${ }^{2}$, Natacha Frachon ${ }^{3} \&$ Heather McHaffie
}

The Ecological and Heath Gardens at the Royal Botanic Garden Edinburgh were created in 1991 and 1997 respectively. The Ecological Garden started as a naturalistic area of native woodland plants where cryptogams were encouraged to grow. Building on its success other habitat types were created nearby. The Heath Garden replaced an older heather garden and sought to recreate the 'feel' of a Scottish upland heathland. In recent years additional wild origin material of conservation concern has been added to each Garden and this paper describes the process along with some of the plants selected.

\section{INTRODUCTION}

Recent plant collecting for the Scottish Heath Garden and the Ecological Garden at the Royal Botanic Garden Edinburgh (RBGE) has involved staff from the Horticulture Division working together with conservation staff from the Science Division. On joint field collecting excursions the horticulturists provide the 'muscle', transport, cultivation and horticultural skills while the scientists provide knowledge such as the locations of plant populations along with their conservation status and also arrange permits for collecting.

The Ecological Garden and the Heath Garden are located at opposite corners of the RBGE from each other and are designed to represent very different kinds of habitat. The Ecological Garden has lime-rich soil with species that can mostly be found on lower ground while the Heath Garden has an acidic soil and includes upland vegetation. This paper is an account of the rationale and hard work that has been devoted to the two gardens. A description of some of the species that grow in them and how they were collected follows.

\footnotetext{
1 \& 2 Gordon Schofield and Andrew McGinn are Horticulturists in the Outdoor Living Collections Department at the Royal Botanic Garden Edinburgh.

Address: 20A Inverleith Row, Edinburgh EH3 5LR.

Email:g.schofield@rbge.ac.uka.mcginn@rbge.ac.uk

${ }^{3}$ Natacha Frachon is co-ordinator of RBGE's Target 8 (of the GSPC) Project.

Address: As above.

Email: n.frachon@rbge.ac.uk

${ }^{4}$ Heather McHaffie is co-ordinator at Royal Botanic Garden Edinburgh's Scottish Plant Project which is run in conjunction with Scottish Natural Heritage $(\mathrm{SNH})$

Address: As above

Email: h.mchaffie@rbge.ac.uk
} 


\section{THE HEATH GARDEN}

The present Heath Garden was planted in 1997 to replace a heather garden that was first established in 1935. The Garden had consisted of a number of species and cultivars of Calluna, Erica and Daboecia but it was past its best and since it had been more than fifteen years since the last renovation a decision was made to change the area. The existing plants had become old and woody and maintenance was becoming more and more difficult due to an infestation of perennial weeds. To combat the weeds the area was cleared completely and left fallow for a year to ensure complete eradication.

During the time that plans for the replacement garden were being discussed a decision was made that it should fulfil a more educational role and it was therefore designed to contain native plants that would create a natural haven for wildlife in a realistic Scottish countryside setting. Hard landscaping was installed first based on a completely new layout. Paths were constructed, tons of soil moved and large stones (trachyt basalt) manhandled in as landscape features. A lochan was created using a rubber liner, peat blocks were used to cover the liner to create a more natural looking effect and a simulated abandoned croft was built utilising some recycled material from the old heather garden.

Plants were obtained from a variety of sources and several of the large trees and shrubs were kept from the previous design even though they were not native. This is often the case in old botanical gardens and in this situation they were kept because

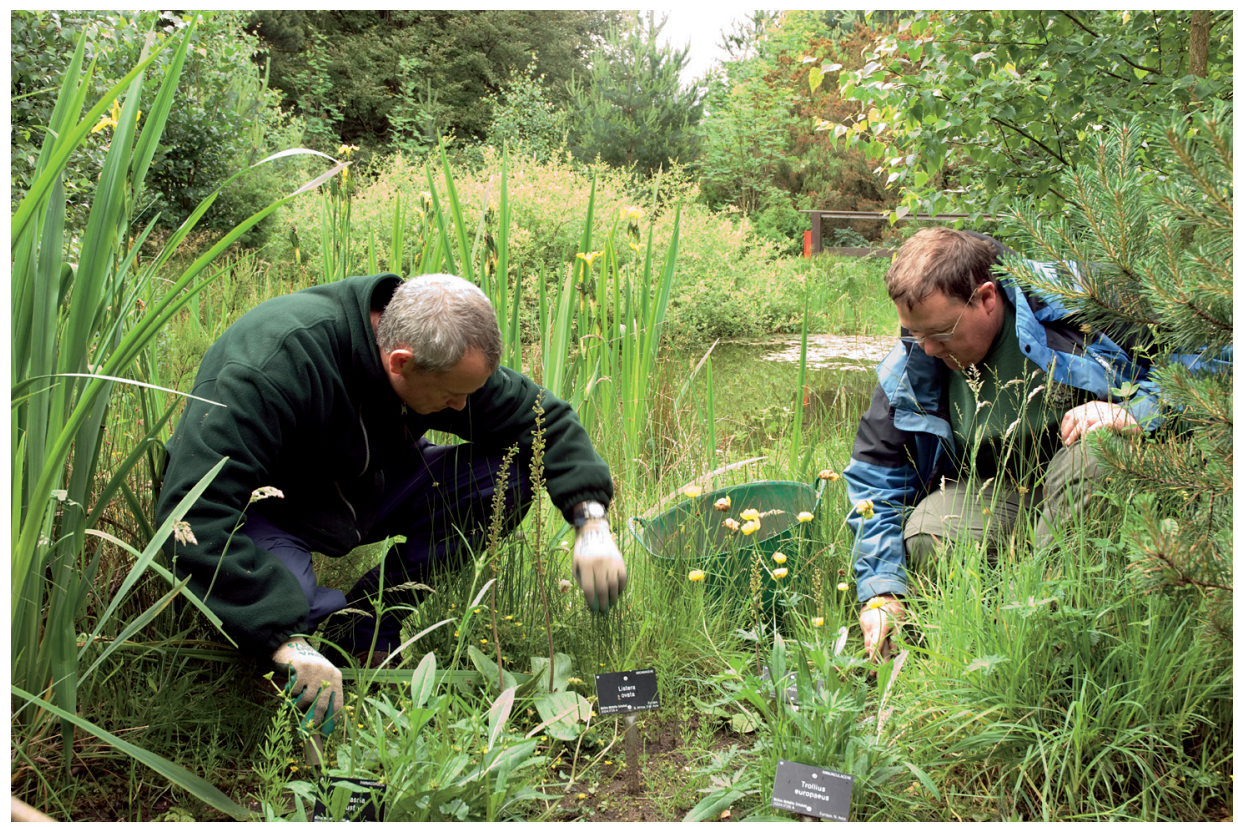

Fig. 1 Gordon Schofield and Andrew McGinn in the Heath Garden clearing the ground around Listera ovata and Trollius europaeus to prevent smothering by weed species. Photo: Lynsey Muir. 
they were of botanical importance and gave structure to the new design. Many plants were moved from other parts of the garden and others were newly obtained, wild origin material collected as whole plants, cuttings or seed. The site was half a hectare in size and the whole process of redevelopment was undertaken in a series of stages lasting four years in total. When fully planted up it contained 140 different taxa and 3266 individual plants with new plants being added all the time. All new, wild origin material was collected with full supporting collection details. This meant that the exact location using GPS co-ordinates was recorded along with notes on associated plants, soil type and topography. This means that the maximum possible information about the plant in the wild had been recorded including any genetic variation so that, were a reintroduction programme to be required due to reductions of the plant in the wild, then it would be possible to use this carefully collected, recorded and managed material for the purpose.

The Scottish Heath Garden has mass plantings of upland plants that are commonly found growing together in the Scottish hills such as Calluna vulgaris, Betula pendula and B. pubescens, Pinus sylvestris, Ulex europaeus, Juniperus communis, Vaccinium vitis-idea, V. myrtillus, Alnus glutinosa and Sorbus species. More recently, additional species have been added for example, Rubus chamaemorus which is often found growing under Calluna on blanket bogs and so it has been placed on the margin of the peaty pool. In peat bogs Drosera rotundifolia grows in the damp sphagnum moss and so it has also been planted at the edge of the pond where Potamogeton polygonifolius rafts out across the water. In drier areas in the wild Listera cordata frequently grows under Calluna vulgaris and to replicate this it is now growing on a heathery bank in the Heath Garden. With the creation of the right habitat the scene is now set for the addition of less common species such as Pyrola media which is a declining species.

Although many of the plants mentioned above are relatively common, they provide both an educational resource and a pleasing environment for recreation and relaxation. Since its completion the Heath Garden has been used in several ways. First, to give visitors who might not be able to gain access to the wilder parts of our countryside a representation of the places in which our native plants grow and to show how varied that plant life is. It is also being used for educational purposes through the Flora Celtica project. The purpose of this project is to inform people and make them more aware of how native plants are used now and have been used in the past by ethnically Celtic communities for, for instance, food, medicines, fabric dyes, building materials and also in folklore. As a direct contribution to science some of the plants in the garden are being used in a Garden-wide phenology study that records the date and month when each plant flowers and sets seed. This is an ongoing project, the purpose being to monitor seasonal variation and provide a record of climate change (see Harper, Mann and Thompson, 2004). The Heath Garden has now become a popular location to sit and relax in pleasant surroundings, part of the attraction being the abundance of wildlife which includes dragonflies, frogs and numerous types of birds and foxes that can be seen making use of the plants and the ecosystem throughout the year. Last of all we are also helping 
to conserve endangered plants and there are several species of conservation concern growing in this area.

\section{THE ECOLOGICAL GARDEN AND CRYPTOGAMIC GARDEN}

These two areas were originally created as two separate gardens. The alkaline grassland part was created five years after the Cryptogamic Garden, both replacing an earlier rose garden and shrub bed. Over time the two gardens have blended into one as a result of their close proximity and because of their similar type and design. It was also allowed to happen as, even though it was not officially planned in this way, they showed the habitats very well.

Work began on the Cryptogamic Garden in early 1991 following a suggestion from Roy Watling, a mycologist at RBGE (see the paper by Prof. Roy Watling in this issue of Sibbaldia). It was officially opened in September 1992 by the late Magnus Magnusson OBE. The original purpose of the area was to have a small plot of semi-managed nativelooking woodland within the grounds of RBGE that would not be manicured to the same levels as the rest of the garden and in which broken branches and leaf litter would be left to allow and encourage the colonisation of fungi. When fruiting bodies appeared in the autumn Prof. Watling labelled them for the benefit of students and the public. It is a woodland area mainly of Betula pendula, Alnus glutinosa, Corylus avellana and other woodland plants that were collected from Saltoun Forest in East Lothian. 'Cryptogam' is a convenient collective name for several groups of unrelated non-flowering organisms, such as mosses, liverworts and algae, as well as fungi and lichens. During the past year several species of fern have also been added to increase the diversity of the area.

The other part of the Ecological Garden has an area representing calcareous grassland that was created in 1997 with a small rocky limestone outcrop for more lime loving species such as Gymnocarpium robertianum. Natural lime-rich habitats such as this one are present in Scotland in the north west, for instance, near Ullapool and the turf in the grassland was originally taken from this area when a limestone quarry was being extended. Inevitably, the turf has lost some of its original character as it does not have the limestone underneath and, as a result, more vigorous acid loving grasses have begun to thrive. To combat this Rhinanthus minor has been introduced. This is a hemi-parasitic plant depending partly on the roots of other plants for their nutrients and its introduction will hopefully reduce the vigour of the grass. There are also plans to spread some ground limestone on the grassland to decrease the acidity and help to redress the balance. Additional species are also being added to the grassland to improve its biodiversity such as Solidago virgaurea, Cirsium heterophyllum and Anthyllis vulneriana. There are two other areas of interest, one beside the grassland on the east side where there is a collection of hybrid willows as well as some other plants which include Lychnis viscaria, Alchemilla glaucescens, Trollius europaeus and Paris quadrifolia. The other is to the north of the grassland in a semi-wooded area where there is a pond with aquatic and marginal plants such as Nuphar pumila, Lythrum salicaria, Eriophorum vaginatum and Lysimachia thyrsiflora. 


\section{THE ROLE OF CONSERVATION COLLECTIONS}

Wild-collected species are continually being added to these two gardens. The existing planting has the aesthetic and educational benefits discussed earlier and forms the background to new planting but species are increasingly being added because of concern over their conservation status. Many species are declining in the wild, usually through loss of habitat, and less common species are often restricted to fragmented habitats with little ability to spread or respond to climate change. By maintaining populations of these vulnerable plants growing in the botanic garden hopefully as much genetic diversity can be conserved as possible and made available should recovery work become necessary. Growing native plants in this way also provides an opportunity for horticulturists to learn more about how the plants grow and how to develop and improve techniques for cultivating and propagating them. Plant collecting for these areas is also helping towards RBGE's target of continuing to increase the proportion of wild origin, known provenance plants in the collection by $1 \%$ a year. These collections are also a response to Target 8 of the Global Strategy for Plant Conservation (GSPC) which aims to have $60 \%$ of Scottish threatened species in ex-situ collections by 2010 (see Frachon, Jebb and Rae, 2005).

\section{STEPS TO BE FOLLOWED BEFORE COLLECTING SEED OR PLANTS}

The first step is to determine the location of the plant in the wild. This is most easily achieved at RBGE by consulting with the Science staff, searching for references in the library or checking herbarium records. For the more common species nothing better can substitute for spending time in the hills looking for plants and taking note of the different species found and their exact location (determined with a GPS), preferably in accessible areas, so that it is possible to find them again. However, before any plants are collected, permission must be obtained from the land owner and, if they are growing within a designated area such as a Site of Special Scientific Interest (SSSI), permission must also be obtained from Scottish Natural Heritage (SNH). This must

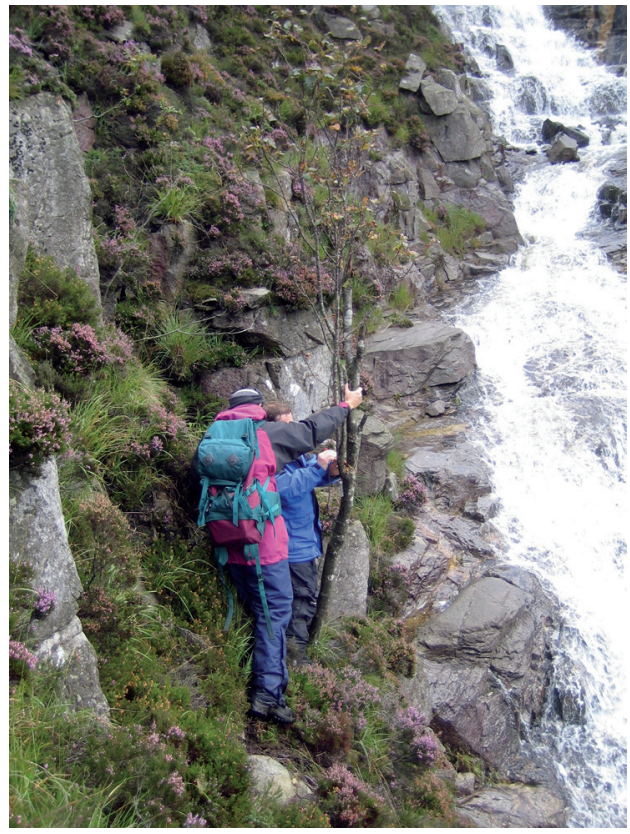

Fig. 3 Gordon Schofield and Andrew McGinn collecting seeds for the project on the island of Arran. Photo: Natacha Frachon. 
state the exact species to be collected and the quantities involved. To ensure that the maximum possible genetic variation is obtained seed is normally collected from at least three separate plants or clumps. Failing this plants are collected if this is allowed and is possible. Material has been collected from all over Scotland, from bogs in the Southern Uplands, the Central Highlands, a privately owned wood regeneration project near Ballater, a woodland in Kintyre and from the island of Arran off the south west coast of Scotland (Fig. 3).

\section{COLLECTION AND CULTIVATION}

There are three options for collecting plants - taking cuttings, collecting seed or transplanting the entire plant from the wild and planting it in the garden immediately on return to Edinburgh. There are advantages and disadvantages to each method and the method chosen will depend partly on the plant in question. For supplementing Erica tetralix in the Heath Garden cuttings were the obvious choice, as they root easily. For Solidago virgaurea and Eriophorum vaginatum seed worked well. The seeds were sown, germinated and grown in the nursery and well-rooted plants were eventually planted out two years after collecting them from the wild. Transplanting the entire plant with roots is the least favoured option for obvious conservation reasons but this has been used on a few occasions with plants that are particularly difficult to grow from seed or cuttings or where seeds or cuttings are difficult to obtain such as Rubus chamaemorus and Dryopteris $x$ sarvelae. When there is a robust population in the wild taking a clump will not have any detrimental effect if it is done carefully. This is also the only way to collect hybrids if cuttings cannot be collected or rooted. However, great care is always taken to leave minimal environmental impact in the wild habitats and only the smallest quantity necessary is taken. Records are taken and all plants, seeds and cuttings are carefully labelled. Where appropriate they are taken to the nursery at RBGE for immediate propagation as cuttings and lifted plants are susceptible to dehydration and some seed is best sown fresh. In the open garden suitable areas for planting are selected and prepared in advance, bearing in mind the habitat the plant came from and whether it needs shade or an open position or if it came from a wet or dry area. Care must be taken in establishment and after-care such as the removal of weeds and provision of water in summer. Some plants come from higher altitude moorland so they are slower growing and can easily be swamped out by more vigorous weed species in the Edinburgh garden such as the invasive Equisetum arvense. A considerable amount can be learnt from growing the plants and observing them and as a consequence there will be a better understanding of their requirements and growth habits which will add to our knowledge of how to conserve them. 


\section{PLANT PROFILES OF SOME RECENTLY COLLECTED SPECIES}

Rubus chamaemorus is a spreading, mat forming perennial with shiny, lobed leaves, and white flowers (Fig. 2). It occasionally produces orange berries. It grows on wet moorland among Calluna vulgaris. The plants in the Heath Garden were collected from the Moorfoot Hills and are now growing in the peaty, damp area beside the pond.

Potamogeton polygonifolius is an aquatic or semi-aquatic with reddish, oval, floating leaves and tiny greenish flowers on knobbly spikes which are held above the water in summer. The flower has no petals but has four sepals and four stamens and the spikes often sink as the fruits develop, each with 4 nutlets. The plants at RBGE came from the Highlands near Blair Atholl and were collected as whole plants. They are growing well in the margins of the pond in the Heath Garden.

Drosera rotundifolia is an insectivorous plant which grows in bogs sometimes among sphagnum moss (Fig. 4). It has reddish leaf hairs which exude dew-like drops of sweet viscous liquid which attracts and briefly impedes small insects. The leaf hairs then bend over trapping the struggling insects which are digested to provide nutrients. The rosettes of rounded leaves are $4-10 \mathrm{~mm}$ across, abruptly narrowing into a hairy stalk to $30 \mathrm{~mm}$ long. The flowers appear in summer on leafless stalks up to $10 \mathrm{~mm}$ tall, but often remain closed, shedding their pollen internally. When they do open, they are $6 \mathrm{~mm}$ across with 5 or 6 white petals.

The plants in the Heath Garden were collected from a peat bog in the Moorfoot Hills are now growing in two patches in the sphagnum moss at the margins of the pond. They die back completely in winter but reappear in spring or early summer. We are hoping to establish a self-perpetuating population.

Listera cordata is a small plant which grows well, hidden beneath clumps of Calluna. It has two opposite heartshaped leaves, 10-20mm long, about one third of the way up the stem. It flowers in early summer, producing

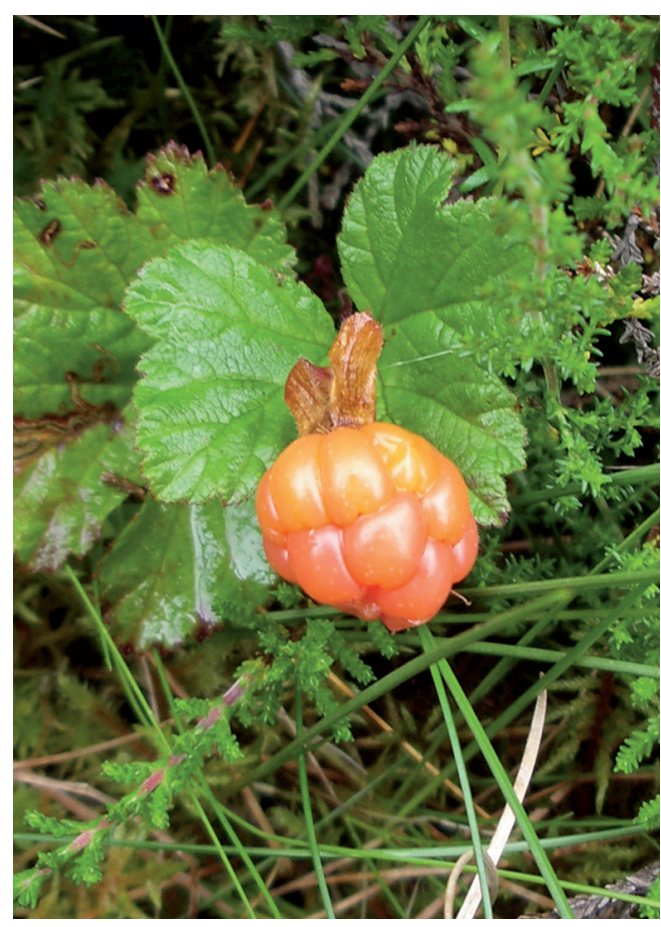

Fig. 2 Rubus chamaemorus (Cloudberry) fruit. This species tends to spread vegetatively and fruit production in Scotland is rare. Photo: Heather McHaffie. 


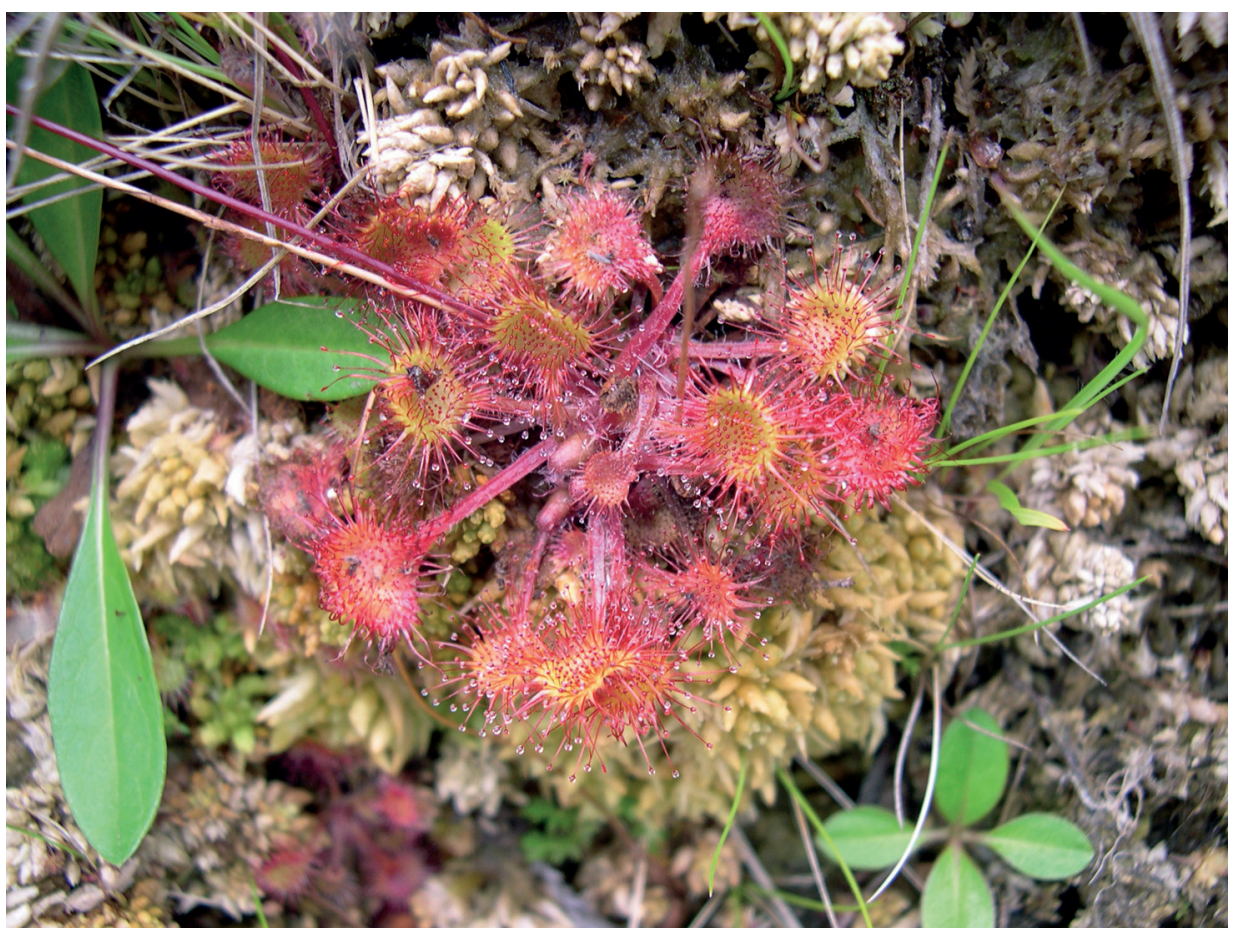

Fig. 4 Drosera rotundifolia (Common Sundew). Minute flies can just be seen trapped on the leaves. Photo: Heather McHaffie.

a spike of 3-15 tiny reddish-green flowers with spreading sepals and upper petals and a deeply forked lip up to $4 \mathrm{~mm}$ long. The plant in the Heath Garden was collected from moorland in a regeneration project near Ballater. It has been planted amongst the Calluna on the bank on the east side of the pond.

Listera ovata is the larger of the two twayblades. It has a single pair of broadly oval, ribbed leaves, 50-200mm long at the base and a sturdy hairy stem up to $600 \mathrm{~mm}$ tall on which it produces a loose spike of yellowish-green flowers with hooded upper lobes, two side lobes like arms, and a long deeply forked lower lip. The plant in the Heath Garden was collected from boggy ground next to a loch in the Central Highlands. It is now growing in the wet area on the east side of the pond.

Vaccinium oxycoccus is an evergreen undershrub found in bogs and wet moorland in central and southern Scotland and the central Highlands, becoming much rarer in the far north. It has thread-like stems with sparse, alternating, untoothed, oval leaves $4-8 \mathrm{~mm}$ long and broadest near the middle. Its flowers are held erect in summer on slender, finely hairy stalks up to $30 \mathrm{~mm}$ long and have four pink petal-lobes which curl back, displaying 
a beak made up of yellow stamens. Its large, round, red berry is edible. The plant in the Heath Garden was collected from the Moorfoot Hills and has been planted in the margins of the pond (Fig. 1).

Solidago virgaurea is a perennial with leafy, little-branched stems up to $750 \mathrm{~mm}$ tall, (although usually much shorter in exposed mountain sites) with narrow, slightly toothed, and stalked lower leaves, and narrower unstalked upper leaves. In mid to late summer, it produces spikes of yellow flowerheads up to $10 \mathrm{~mm}$ across with 6-12 spreading rays, surrounded by several rows of overlapping, greenish-yellow bracts. Seed was collected in 2005 from a rocky ledge in the Southern Uplands, germinated and grown on in RBGE's nursery and planted out in November 2006 as a mass planting in the grassy area in front of the croft in the Heath Garden.

Erica tetralix. This evergreen dwarf shrub up to $600 \mathrm{~mm}$ tall prefers wet ground on bogs and moorland. It has greyish, hairy, needle-shaped leaves, with down-curved margins hiding the under surface to retain moisture. The leaves are arranged in regular cross-like whorls of four up the stems. In the summer, it has compact, one-sided clusters of 4-12 drooping flowers. These have paler pink petal tubes compared with Erica cinerea and are $6-7 \mathrm{~mm}$ long, with short, hairy, grey-green sepal lobes. The Heath Garden plants were collected as cuttings from a newly planted woodland site near Ballater. They were rooted and grown on in the nursery, before being planted in blocks in the Heath Garden in November 2006. All the ericaceous shrubs tend to become woody and need to be replaced periodically as it is not practical to have rotational burning, which is how regeneration occurs in the wild.

Eriophorum vaginatum grows up to $600 \mathrm{~mm}$ tall and forms tussocks of narrow leaves. The flower stem is sheathed by two to three inflated leaves and in spring has a solitary oval head of yellowish flowers without bracts below. These develop by early summer into a dense fluffy white head. The plants in the Heath Garden were collected as seed from near the roadside in the Moorfoot Hills in 2004, germinated and grown in the nursery, before planting November 2006.

Pyrola media is a short, creeping perennial up to $400 \mathrm{~mm}$. The white, spherical flowers appear from June to August and are $7-11 \mathrm{~mm}$ across with a style $4-6 \mathrm{~mm}$ long that just protrudes from the flower. It has leaf stalks that are longer than the length of the rounded leaves. This is a vulnerable species which grows in moors and woodland and is a conservation priority. Many of the English populations have been lost but there are still many good sites in Scotland. The plants we collected were obtained from a site near Ballater with large healthy populations and have been placed in the Heath Garden and nursery. This is one of the species covered by Target 8 of the Global Strategy for Plant Conservation (GSPC), and is one of the 21 GSPC species included in the two conservation gardens at Inverleith. 
Trollius europaeus has yellow flowers and grows in marshy ground with some seepage of lime-rich water. It grows up to $600 \mathrm{~mm}$ tall with leaves that are rounded in outline but deeply cut into 3-5 spreading lobes that are toothed and divided. The plants growing in the Heath Garden were collected from near Blair Atholl (Fig. 1).

Anthyllis vulneriana. This plant prefers sunny, lime-rich cliffs near the sea and mountains inland. It is a silky haired perennial with stems to $600 \mathrm{~mm}$ tall and leaves to $140 \mathrm{~mm}$ long with 3-7 pairs of narrowly oval leaflets, topped by a broader leaflet. In summer it has crowded, roundish, usually paired heads to $40 \mathrm{~mm}$ across of tightly compressed yellow pea flowers with woolly sepal tubes and longer yellow or reddish petals. This plant was wild collected from Crianan Ardrie cliffs at Largybaan, Kintyre and has recently been mass planted in the grassland in part of the garden.

Athyrium distentifolium. This is a small montane fern species usually 200-300mm but occasionally up to $700 \mathrm{~mm}$, only distinguishable by its rounded (not curved) spore-cases, whose covering flaps fall off quite early. The spores ripen from July to August and it grows in screes in the Scottish Highlands. The plant in the Ecological Garden was collected from Glen Doll in Angus and is now growing in the margins of the woodland area.

Dryopteris expansa. This is a fern species with rufous scales and pale yellow-green triangular fronds from May to November. Spores ripen from August to September. It grows in hills and mountains in the Highlands. The plant in the Ecological Garden was wild collected from Meal Bhuidhe near Bridge of Orchy, Argyll and is now growing in the margins of the woodland area.

Polypodium cambricum. This is a fern species with yellow-green fronds which are not leathery, the lowest pair often held upwards, making the fronds appear narrowly triangular. The spores ripen from December to May. This plant was wild collected from St. Germans railway station in Cornwall and is now growing in the limestone crag in the ecological grassland area of the Ecological Garden.

Asplenium trichomanes. This is a small fern species with a tuft of long narrow overwintering fronds $50-200 \mathrm{~mm}$ in length. The fronds are oval - oblong and slightly toothed. Stalks and midribs are blackish. Scales on the rootstock have a dark central stipe. Spores ripen from September to October. It grows in walls and limestone rocks, mainly on the west of Scotland. The plant in the Ecological Garden was wild collected from Kindrogan Enochdhu in Perthshire and is now in the limestone crag in the grassland area. 


\section{CURRENT AND FUTURE WORK}

The development of the areas continue with the implementation of new projects. Heather McHaffie is currently embarking on a project to collect seed of montane willows (Salix ssp.). These will be sown and grown in the RBGE nursery and the resulting plants will be used to increase wild populations in a repatriation programme. This project is being run in conjunction with Scottish Natural Heritage. A new bed is also being created in the Ecological Garden in order to display a representation of the recently collected plants. In this way and when carefully interpreted the plant collections on display can help to explain the conservation work of RBGE.

\section{CONCLUSION}

RBGE is well known for its collections of exotic plants, especially those from places such as China, Nepal and Chile. While the Garden has always cultivated quite a few native species, until about fifteen years ago these were scattered throughout the collection without any real focus. The creation of the Ecological and Heath Gardens have made possible the display of native plants within appropriate ecological settings. Working in conjunction with staff from the Science Division, horticultural staff have been slowly, but steadily, adding wild-collected species of conservation concern to fulfil GSPC and other targets. Joint projects of this type, which bring together horticulturists, scientists and conservationists, in conjunction with external collaborators, frequently work very well as exemplified by this project.

\section{REFERENCES}

HARPER, G. H., MANN, D. G. AND THOMPSON, R. (2004). Phenological Monitoring at the Royal Botanic Garden Edinburgh. Sibbaldia: An occasional series of horticultural notes from the Royal Botanic Garden Edinburgh, 2, 33-47.

FRACHON, N., JEBB, M. AND RAE, D. (2005). PlantNetwork's Target 8 project - The survey stages. Sibbaldia: An occasional series of horticultural notes from the Royal Botanic Garden Edinburgh, 3, 67-83. 
